\title{
O TEMPO E O DIREITO SOB O ENFOQUE DO MEIO AMBIENTE
}

Time and right under the focus of the environment

Sérgio Augustin ${ }^{1}$

Eliane Oliveira Borges ${ }^{2}$

Natacha Souza John ${ }^{3}$

\begin{tabular}{|c|c|}
\hline RESUMO & ABSTRACT \\
\hline $\begin{array}{l}\text { O presente estudo trata de forma breve sobre o tempo e } \\
\text { suas relações com o direito e com o meio ambiente. } \\
\text { Inicialmente, apresenta-se o pensamento de diversos } \\
\text { autores na tentativa de definir o tempo. Depois, a partir } \\
\text { da obra "O tempo e o direito" de François Ost, faz-se a } \\
\text { tentativa de melhor relacionar o tempo com as relações } \\
\text { sociais e jurídicas, firmando-se a convicção que não se } \\
\text { pode falar em Direito sem falar em tempo e vice-versa. } \\
\text { Finalmente, faz-se um breve estudo das relações do } \\
\text { tempo com o meio ambiente, em especial, com a } \\
\text { necessidade de agilidade na sua preservação }\end{array}$ & $\begin{array}{l}\text { This study focusses briefly on the time and this } \\
\text { relationship with the law and the environment. Initially } \\
\text { it presents the tinking of several authorsin an attempt } \\
\text { to the set the time. Then, from the book. "The time and } \\
\text { right" of François Ost, it is na attempt to better relate } \\
\text { time with social and legalrelations, confirming the } \\
\text { belief that one call nottalk about rights without talking } \\
\text { about time andviceversa. Finally, it is a brief study of } \\
\text { time relationship with the environment, in particular } \\
\text { the need for agility in its preservation. }\end{array}$ \\
\hline Palavras-chave: Tempo; direito; meio-ambiente. & Key words: Time;right;environment. \\
\hline
\end{tabular}

\section{INTRODUÇÃO}

O objetivo do presente trabalho é avaliar as possibilidades do Direito e do tempo sobre o meio-ambiente. Tal verificação será feita analisando as interfaces do Tempo e do Direito, sob o enfoque do meio-ambiente, em especial a sua manutenção em condições dignas para as presentes e futuras gerações, onde é ressaltada a importância da aplicação dos princípios da prevenção e da precaução, assim como medidas eficazes de proteção dentro de um tempo razoável. Mais do que proporcionar resultados definitivos, procura-se possibilidades, de que de alguma forma, possam contribuir para pesquisa em um debate futuro.

\footnotetext{
1 Doutor em Direito pela UFPR, coordenador da Pós-Graduação em Direito da UCS, Juiz de Direito. natachajohn@hotmail.com

2 Professora do Centro de Ciências Jurídicas - UCS, mestranda em direito ambiental pela UCS. natachajohn@hotmail.com

${ }^{3}$ Mestranda em Direito Ambiental pela Ucs, advogada. natachajohn@hotmail.com
} 
180

Iniciando a análise na tentativa de definir o significado do tempo, passa-se uma tentativa de relacionar o tempo com a relações sociais e jurídicas, para estabelecer uma ponte entre as necessidades presentes e o interesse do futuro, através de uma promessa de um futuro socioambiental sustentável.

Tendo em vista, a complexidade da modernidade deve ser analisada as formas que o Direito pode institucionalizar a mencionada promessa, para conseguir sua concretização. Assim, a efetividade do cumprimento da promessa passa pelo ajustamento dos interesses do presente e do futuro em face das especificidades temporais e referenciais com o meio ambiente em especial, com a necessidade de agilidade na sua preservação

\section{TENTATIVAS DE DEFINIÇÃO DO TEMPO}

O tempo é um mistério que desafia e envolve o pensamento humano, e por isso, desde há muito tem sido objeto de estudos e reflexões na tentativa de encontrar-se uma resposta real ao fenômeno.

No século IV Santo Agostinho (2004,p.338) indagava-se sobre o tempo e a si mesmo respondia: “(...) o que é o tempo? Se ninguém me pergunta, eu sei: porém, se quero explicá-lo a quem me pergunta, então não sei."

Pode-se observar que já naquela época e antes dela o tema era de difícil compreensão e nem mesmo o avanço do conhecimento científico dos últimos séculos, com todas as pesquisas mostrou-se capaz de oferecer resposta definitiva sobre a exata denotação do tempo, que pudesse até mesmo responder à pergunta formulada por Santo Agostinho, a qual permanece sem resposta exata há mais de 1700 anos.

A incerteza das respostas para a abundância das perguntas confirma que por mais pretensioso que seja o homem no domínio do conhecimento, continua limitado, inquieto e sem definição diante de muitos fatos da natureza, dentre eles, o tempo.

E, a cada dia necessita-se conhecer mais e melhor esse fenômeno natural, o tempo e o seu passar, cada vez mais precioso e importante nas relações humanas, nas interações do homem com as coisas e com a natureza. 
Teixeira (2009,p.148) diz que o domínio do homem sobre alguns eventos da natureza por meio da tecnologia de ponta, o acelerado conhecimento humano, o mercado econômico caracterizado pela celeridade são alguns fatores que interferem diretamente nas relações sociais e na vida das pessoas em geral, fazendo do cotidiano uma realidade, a cada dia, mais dinâmica e passível de mudanças. Por isso, o tempo, passa a ser encarado como um fenômeno de valor crescente, decisivo, por si só, em muitas questões relevantes.

Embora toda esta importância, os esclarecimentos a respeito do significado e da natureza desse fenômeno não avançaram na proporção do crescimento de seu grau de relevância na vida em geral.

Os esforços dos físicos, matemáticos, sociólogos e filósofos, tem contribuído mas não foram suficientes para desmistificá-lo.

Whitehead (1994, p.10-89) referindo-se ao tempo, diz que as dificuldades de apreendê-lo pelo pensamento decorrem do fato de tratar-se de algo de revelação direta e imediata à apreensão sensível, com fácil percepção pelos sentidos, mas de difícil compreensão e explicação por via da inteligência humana. Declara, ainda, que as meditações a respeito do tempo e dos mistérios da sua passagem criativa não podem ser feitas sem uma grande comoção ante as limitações da inteligência humana.

Continua, o físico inglês $(1994$, p.8) dizendo que a percepção sensível não se vale do pensamento, mas dos sentidos, e é por meio dela que o tempo se esclarece ao homem, tornando-o familiar, elemento perceptível no dia-a-dia, em todos os momentos, em todas as coisas e em todos os lugares.

Porém, quando se busca no campo da inteligência a sua significação, as dificuldades se apresentam. Agora o tempo, sempre presente e sentido, passa a ser notado como um presente desconhecido, dificilmente acessível ao pensamento e á compreensão racional. Isso leva a uma reflexão mais direta a respeito da assertiva de Whitehead (1994,p.9) de que " a natureza está fechada para a mente".

Realmente, a compreensão do tempo continua instigando a mente humana, inclusive sobre a existência de passado, presente e futuro, sobre o fato de ser o tempo passageiro, ou como afirma o autor referido (1994,p.88) que nada é necessariamente presente, uma vez que " a passagem da natureza não deixa nada entre o passado e o futuro". 
Esta visão do tempo em que o presente se manifesta com maior amplitude de duração, envolvendo, de forma mal definida e sem delimitação clara de divisas, momentos passados e futuros, pode ser sentida pelo homem. Porém, estas indefinições não estão relacionadas ao tempo em si, mas às limitações da inteligência humana.

Prigogine (1996, p.169-192) por sua vez, ao tratar do tempo escreveu numa parede da Universidade Lomonosoff, em Moscou, no ano de 1985, que "o tempo precede a existência".

Na tentativa de explicar o que escreveu, discorre sobre a importância da Teoria da Relatividade Geral de Einstein, perpassa pela física newtoniana, ampliada pela física quântica, cita Hawking e o big-bang para finalmente declarar que "o tempo é eterno". Diz que, todos, temos uma idade, a civilização tem uma idade, o universo conhecido tem uma idade, mas o tempo, por seu lado, não tem começo nem fim.

Contudo, refere que esta hipótese implica elementos especulativos, mas diz que é interessante que concepções cosmológicas que se valem do papel do tempo e da irreversibilidade possam ser formuladas de maneira mais precisa do que era a idéia de caos.

Sabe, contudo, que a "verdade última, está, contudo, ainda muito distante".

Em sua obra O fim das certezas (1996,p.191) apresenta duas características gerais de sua abordagem do tempo:

\footnotetext{
Por um lado, é claro que, mesmo antes da criação de nosso universo, havia uma flecha do tempo, e que essa flecha não tem nenhuma razão para desaparecer. Por outro lado, reencontramos os dois elementos que pusemos no centro deste livro, a irreversibilidade e a probabilidade. Os universos aparecem ali onde as amplitudes dos campos gravitacionais e massivos tem valores altos. O lugar e o momento em que isso acontece tem apenas um significado estatístico, pois estão associados às flutuações quânticas.
}

As ideias acima referidas não se aplicam, portanto, somente ao nosso universo, mas também ao meta-universo, isto é, a um meio no interior do qual um número indefinido de universos individuais pode nascer. Ideia bastante difundida entre outros autores.

Ou seja, para um leigo, nada pode ser compreendido, ou pelo menos, quase nada se entende das colocações do autor. Porém, como já foi dito, aí reside a dificuldade de 
compreensão mental do que é o tempo. Continua-se, basicamente na compreensão - ou apreensão- sensível do que é o tempo.

$\mathrm{O}$ autor refere que Einstein perseguiu, durante sua vida, o sonho de uma teoria unificada que incluísse todas as interações. Prigogine conclui que a realização desse sonho exigiria uma concepção evolutiva do universo. E esta unificação implicaria, portanto, uma concepção dialética da natureza.

Finaliza, dizendo que "a questão do nascimento do tempo e a das origens permanecerão, sem dúvida, sempre de pé” (p. 191).Complementa fazendo a reflexão de que uma vez que a teoria da relatividade geral não é fechada como se pensava, como tampouco a mecânica clássica ou quântica, a possibilidade de que o tempo não tenha começo, de que o tempo preceda a existência do universo, se torna uma alternativa razoável.

Portanto, como se vê, a formulação de uma teoria para explicar o paradoxo do tempo, é em si, um exemplo da criatividade e imaginação humana, porém sem definição concreta, material, definitiva, a sociedade convive com as incertezas temporais, em busca de uma melhor compreensão das leis da natureza

\section{O TEMPO E O DIREITO EM FRANÇOIS OST}

Leonel Severo Rocha em seu artigo Tempo e diritto: dal normativismo all'autopoiesi, com propriedade diz que uma das melhores observações do Direito do ponto de vista temporal é feita por François Ost na obra O tempo do Direito.

Cita, ainda, Castoriadis, o qual defende a tese de que "non esistono Tempo, Diritto e Societá isolati, cio é Il Diritto é un'istituzione immaginaria nella quale Il Tempo costruisce ed é costruito, istitutisce ed é istituito".

Nestas perspectivas, passamos a examinar, mesmo que de forma breve, as relações entre o tempo e o direito pelos olhos e pensamentos de François Ost, o qual recorrendo à mitologia grega, à filosofia predominantemente clássica e às ciências sociais e políticas, dedica-se a tomar a medida do direito; o direito como medida, pelo menos em quatro 
184

sentidos: 1) decisões e regras de conduta; 2) instrumento de medida com o qual se avalia a justa proporção das relações, a importância das prestações e dos prejuízos, a igualdade dos direitos e dos deveres; 3) expressão do justo meio termo, equilíbrio, moderação, prudência (jurisprudentia); 4) "temperamento" que se apresenta no trabalho de ajuste permanente, em ritmo conveniente, é harmonia de durações diversificadas, a escolha do momento oportuno, o tempo atribuído à marcha do social.

Em sua reflexão, OST indica quatro categorias de tempos normativos e temporais, quatro figuras da retemporalização: memória, perdão, promessa, questionamento. A memória liga o passado, assegurando a identidade histórica: registro, fundação e a transmissão. É seletiva, criadora, é tanto esquecimento quanto comemoração.

A tradição é evolutiva e histórica; o precedente judiciário, como o costume, são reelaborados em função das necessidades do presente. O perdão desliga o passado, imprimindo-lhe um sentido novo.

Desliga-se do passado, nem por isso se aniquila. Como diz OST, "se a ofensa é superada,ela não é esquecida, nem realçada, e se acontece ao juiz constitucional invalidar uma lei, é para restaurar o primado de uma norma superior".

Estas anulações servem, também, para administrar o passado e a segurança jurídica, com referência aos efeitos de norma inválida. O juiz desliga do passado quando, ao término de reviravolta de jurisprudência, liberta-se de uma linhagem de precedentes tornados ultrapassados.

A promessa liga o futuro por meio dos comprometimentos normativos. Segundo François Ost, o juiz é o "guardião das promessas": aplica aos fatos históricos uma norma previamente estabelecida e "exprime o direito no respeito pela segurança jurídica".

No centro da cadeia normativa, a Constituição figura como promessa que a nação faz a si mesmo, apresentando uma concentração de valores fundamentais que a define como instituição durável. Segundo Habermas, à ideia de uma sociedade justa associa-se uma promessa de emancipação e de dignidade do homem.

Enfim, o questionamento desliga o futuro com objetivo de assegurar as revisões necessárias para que sobrevivam as promessas na hora da mudança. Exprime a radicalidade do gesto emancipatório da crítica. Nutre a trama do tempo, diante de um futuro que é 
contingente, que se abre e pode ser marcado pelo acesso de todos ao mercado livre, em uma sociedade aberta, livre de ideologias funestas e de previsões enganosas que lhe entravam o curso.

Cada categoria é uma condição necessária para uma temporalização bem sucedida, mas, nenhuma delas é condição suficiente. A dialética temporal opera no presente e a dialética opera no núcleo de cada categoria: há muito esquecimento na memória e muita memória no perdão; da mesma forma, há muita indeterminação na promessa e muita fidelidade na revisão.

A justa medida destes quatro tempos, sistematicamente misturados, constrói o ritmo do direito e se desenvolve no presente, a que OST se refere como "enigma central do tempo", com "terceiro tempo", "motor de todas as dialéticas". O presente opera como "grande embreagem" do tempo, garantindo o acoplamento eficaz de suas forças, a tração de umas pelas outras. Conforme Nietzsche, "é em virtude da força suprema do presente que se tem o direito de interpretar o passado" e, acrescenta OST, de inventar o futuro.

Todavia, o tempo presente é "um desafio que nada tem garantido". Conquistálo é questão de responsabilidade: "uma questão ética e política mais que uma necessidade ontológica”. Mais além, OST diz que a justa medida dos tempos mesclados é questão de responsabilidade positiva e voltada para o futuro, livre de suas conotações passadistas e culpabilizantes.

O patrimônio diversificado que herdamos do passado é um reservatório de possibilidades. Devemos reinventar sua utilização a cada instante. A "herança sem testamento", eis aí todo o tempo, a necessidade de ligar o passado ao futuro, a força de reinventar o sentido da herança. Preocupado com a durabilidade e, podemos acrescentar, com a qualidade da herança que será transmitida às gerações futuras, OST afirma que "uma duração é medida para permitir fazer justiça; é um tempo dado, para que o direito se enuncie".

Com isto, nos faz pensar na possibilidade de uma reflexão sobre o tempo na política e no direito, a partir de uma nova perspectiva, voltada para esforços mais duradouros que permitam ampliar a compreensão da sociedade do presente e o que ela pode oferecer, concretamente, para a sociedade do futuro, sem nos perdermos na nossa própria história. 
186

Neste contexto, torna-se reconhecível a força humana ativa nos processos de estabelecimento das medidas que nos servem como organizadoras da história e dos limites legitimados e socialmente aceitos. Sob tal visão, as convenções sociais, dotadas de força consensual legitimadora, deveriam delinear caminhos norteadores do futuro.

A temporalização é o tempo das construções sociais. Temporalizar o tempo, reconstruí-lo à nossa medida, a de nossa cultura. $\mathrm{O}$ direito afeta a temporalização e o tempo determina a força instituinte do direito, seu elemento fundante. O direito temporaliza, ao passo que o tempo institui.No entanto, assim como foi instituída pelo direito a “temporalização", surge a "destemporalização”, ou seja, a saída do tempo comum instituinte, a fuga do tempo que se materializa na busca da eternidade ou nostalgia, que gera, por exemplo, ideologias totalitárias.

O Direito pode contribuir para uma destemporalização, quando oferece subsídios para o instantaneísmo (entropia),ausência de mudança (nostalgia da eternidade), o determinismo e a "discronia", que impede a sincronia do tempo histórico social. Vale-se muito de fatores históricos para se justificarem normas, decisões, posturas políticas. Ocorre que nossas instituições se movem pelo imediatismo casuísta, normalmente vinculado a interesses econômicos.

A tese geral da obra de OST é que toda temporalidade que se absolutiza é virtualmente desinstituinte. Permite, com sua obra, uma compreensão retrospectiva de parte do pensamento crítico de Hannah Arendt e das categorias temporárias por ela elaboradas. Os tempos dados à instituição do social representam as condições de um tempo público, fruto de criação do tempo ("temporalização"), em meio ao que Arendt denomina "crise da cultura", em que se vê incapacidade de articular passado e futuro, memória e projeto, em uma cultura demasiada vezes marcada pelo instantaneísmo e pela supervaloziação do presente.

Assim, Ost aponta para o entronamento de pensamento gerado pela representação de um tempo homogêneo e uniforme, pleno e contínuo. $\mathrm{O}$ "determinismo", o pensamento único e o domínio do mercado valorizam a mudança, mas não abrem lugar nem oferecem liberdade para novos caminhos para a liberdade. 
O tempo social é plural. Seu domínio é tanto o da simultaneidade quanto da sucessividade. É fundamental aceitar a necessidade de gestão da policronia para assegurar a coordenação dos ritmos temporais de uma sociedade, sob pena de desintegração da sociedade.

O "risco de discronia" ocorre em sociedades pouco solidárias que acumulam as tensões entre o tempo dos ganhadores e o tempo dos negligenciados, o tempo instantâneo das trocas financeiras, o tempo lento da produção e o tempo muito lento da regeneração da natureza.

A instituição jurídica é tanto ruptura como ligação do tempo. É preciso acentuá-la. Contra a propensão regressiva da eternização é preciso fazer valer o tempo desligado da mudança. Contra a irreversibilidade mortífera da mudança física, é necessário buscar o elo cultural do passado e do futuro, a fecundação reflexiva do projeto pela experiência e a revitalização do dado pelo possível.

Contra o peso do determinismo histórico, é preciso abrir a brecha da iniciativa e da alternativa. Contra as temporalidades manifestas de sociedades hiperindividualistas, é preciso imaginar mecanismos de concordância dos tempos: mecanismos efetivos de integração social, em cada tempo público em que atua (tempo da política, do social, da economia, etc).

As forças instituintes (tempo) se moldarão às formas instituídas (direito), que, com o desenvolvimento social (com o passar do tempo), pedirão para serem substituídas por novos modelos instituintes. Esse ritmo nos conduz à "temperança" que é a sabedoria do tempo, a justa medida da continuidade e da mudança que assegura o equilíbrio das relações sociais. $\mathrm{O}$ direito deve contribuir para esta justa medida que torna livres os cidadãos e harmoniosas as cidades.

Então, o autor avalia a força mensurante do direito, dedicando-se a encarar sua capacidade de transcender suas ordinárias destinações positivistas e rumar à instituição e aperfeiçoamento da sociedade.

Antes de regrar o comportamento dos agentes ou de separar seus conflitos, é preciso, de fato, definir o jogo no qual a ação deles se inscreve. Antes de manejar a distinção entre legal e ilegal, entre permitido e proibido, é preciso criar o quadro geral de interação no seio do qual estas distinções ganham sentido. É preciso construir o edifício antes de regulamentar seus acessos e a utilização de seus compartimentos. 
Sem dúvida, esta função instituinte apresenta uma outra relação com o tempo, além do exercício do comando de que falamos. Ainda que este se acomode com a imediatidade (e até a reclame, desde que se trate de ser eficaz naquele instante), em contrapartida a função instituinte supõe, por hipótese, tempo para manifestar seus efeitos. Nada de uma mobilidade estática (a parada do jogo social), mas a própria possibilidade de jogar, graças ao domínio controlado do jogo e de suas eventuais mudanças.

Alerta de que não se pode mais engajar o futuro em escolhas irreversíveis expõe toda sua preocupação com o tempo presente, que não deve restar comprometido, segundo ele afirma, para que não bloqueemos o futuro, desqualifiquemos o passado e hipotequemos o presente.

A sucessão do dia e da noite, o curso das estrelas e o envelhecimento dos seres vivos (tempo como fenômeno físico) se mesclam às experiências íntimas e às consciências individuais (tempo como uma experiência psíquica), em âmbito coletivo em que se percebe o tempo como produto de construção social denominada "temporização" (tempo como instituição social).

Aqui, o tempo figura como questão de poder, uma exigência ética e um objeto jurídico. O tempo não é exterior às situações, ele participa da sua própria natureza. Neste contexto, pode-se, por exemplo, dar, tomar, perder, passar, encontrar, matar ou ganhar tempo.

O Direito assume contornos de representação. Além de leis e sanções, carrega um discurso que exprime o sentido e o valor da vida em sociedade. Forma-se o elo entre temporalização social do tempo e instituição jurídica da sociedade.

Situados no gargalho estreito da ampulheta, por onde escorre o tempo, podemos, segundo propõe OST, ampliar a discussão histórico-social a respeito do "imbricamento" das convenções temporais e legais que embasam e caracterizam as estruturas sustentadoras das civilizações. Somente nós, seres humanos, podemos "voltar a ampulheta", retomando refletidamente o passado.

A ideia de que existe intervenção direta e recíproca entre tempo e direito, diante de uma perspectiva histórica não-linear, nos oferece, por meio de uma teia reflexiva, elementos consistentes para a compreensão do desenvolvimento da Teoria do Direito, a partir de 
articulação crítica dos conceitos teóricos referentes às categorias temporais e os locus sociais formadores do discurso legal.

$\mathrm{Na}$ sociedade de contornos materialistas, imediatistas e hiperindividualistas, cujo futuro insiste em repetir erros do passado e as grandes novidades ficam expostas no museu eternizado pelo poeta, o tempo não para. Testemunha presencial de tudo que existiu, existe e existirá no Universo, o tempo acompanha a vagarosa evolução social da humanidade e enxerga, atônito, o desperdício de suas potencialidades.

A essência da vida se oculta, cada vez mais, em percursos hipócritas e equivocados nas sociedades degeneradas pela impaciência e pelas contradições.

O tempo, como um dos agentes de maior importância no caminho do aperfeiçoamento. Há formas de "perder” o tempo, e oportunidades de "recuperá-lo". Devemse ampliar tais oportunidades.

Conhecer a linguagem do tempo e atuar inspirado em seus conselhos deve constituir uma das máximas aspirações dos seres humanos, para que se possa alcançar a consciência de seu valor social, transcendendo a escravidão imposta pela ignorância de seu aproveitamento, a fim de se assegurar a coordenação dos vários ritmos temporais de uma sociedade, para que ela não se desintegre, diante de um inoperante Direito.

É preciso combater as patologias temporais (eternidade, entropia, determinismo, "discronia") que promovem o retorno ao estado de natureza, pré-social, onde vige o medo e a violência.

O Estado de direito planeja-se como garantidor eficaz de estabilidade e de segurança, o que não deve avalizar imobilismos e excesso de confiança em algo que se destemporalizou. Por isto, OST considera inconstitucionais as imutabilidades que se operam em detrimento do elo social e da própria confiabilidade, sem se descuidar do fato de que as normas constitucionais exercem função pedagógica em relação às gerações vindouras e, simultaneamente, fixam as orientações pelas quais os textos derivados devem, em princípio, se inspirar.

Deste modo, a norma jurídica deve ser inserida na temporalidade, sem se permitir, com isto, uma mutabilidade absoluta inspirada na tese positivista instantaneísta. 
199

Conforme Hauriou, o Estado não é somente a ordem no espaço; é também ordem no tempo. Deve garantir a existência durável da comunidade histórica. Mas, o Direito não é emanado somente do Estado, mas, também, de diversas ordens sociais.

A história deve ser escrita e reescrita incessantemente, ligando-se e desligando-se o passado, ligando-se e desligando-se o futuro. A sociedade, herdeira de si mesma, deve, no presente, assumir compromissos com avanços políticos e jurídicos, de olho nos outros tempos.

Finalizamos, a apresentação do pensamento do autor, quando ele refere que o Direito pode oferecer mecanismos para se atar e se desatar o tempo histórico, para produzir ou reproduzir ordem social legítima e momentos mais sóbrios que evidenciem amadurecimento político, maior compreensão da Ética e da Justiça e, enfim, encurtamento da sensível distância entre o direito legislado e o direito praticado.

Neste sentido, pretende-se verificar a influência das questões temporais aqui tratadas no que concerne ao meio ambiente, reflexão feita pelo autor em sua obra.

\section{O TEMPO E O MEIO AMBIENTE}

A partir da visão de François Ost de que o domínio da proteção ambiental revela-se um domínio revelador da "destemporalização", cumpre verificar quais as possibilidades de melhoria nas questões ambientais, pelo olhar do tempo.

François Ost diz que o modo de consumo e de produção, o modo de transporte, as formas de ocupação do espaço agravam as tensões entre o tempo curto dos ritmos industriais e o tempo longo da incubação natural, multiplicando-se assim as "bombasrelógios", cujo efeito repercute nas futuras gerações.

No mesmo sentido em sua obra A natureza à margem da lei (1995) refere-se à natureza como o "meio", a interação do homem e do ambiente e discute a sua conformação legal, se seria objeto ou sujeito de direitos.

Entende necessário um estatuto jurídico(uma norma) do "meio", que esteja à altura do paradigma ecológico marcado pelas ideias de globalidade (tudo constitui sistema na natureza) e de complexidade;um regime jurídico pertinente face ao caráter dialético da relação homem-natureza, que não reduza o movimento ao domínio unilateral de um sobre o outro. 
Crê na necessidade deste estatuto conferir uma forma jurídica ao conceito econômico de "desenvolvimento sustentável”, canalizando os modos de produção e de consumo para vias que preservem a capacidade de regeneração dos recursos naturais, e de forma mais ampla, os ciclos, processos e equilíbrios, locais e globais, que asseguram a reprodução do ser vivo.

Este regime jurídico deve, ainda, traduzir a preocupação ética de assumir responsabilidade a respeito das futuras gerações, impondo uma moderação a fim de garantir a igualdade das gerações no acesso aos recursos naturais de qualidade equiparável.

Alexy (2002, p.429) afirma que o Direito Ambiental é um dos mais completos, e o define como "direito fundamental como um todo". E o classifica como: direito de defesa, quando exige que o Estado omita determinadas intervenções ao meio ambiente; direito à proteção, eis que impõe, ao Poder Público, a salvaguarda do meio ambiente, diante de intervenções negativas; direito ao procedimento, ao permitir ao particular a participação em procedimentos relevantes para a defesa e proteção da natureza; direito à prestação fática, ao impor a adoção de medidas voltadas para a melhora da qualidade ambiental.

Mas como estamos tratando sobre o tempo, temos que o meio ambiente experimenta o tempo universal, não sendo alheio, portanto, á temporalidade abstrata e regular, que independe do movimento dos corpos.

Nas palavras de Teixeira (2009), para a natureza a marcação temporal mecânica, em dias, horas, minutos é tão importante como é para atos e fatos verificados no mundo sensível, por estabelecer um parâmetro de observação regular dos acontecimentos. Porém, o meio ambiente tem sua própria e específica realidade temporal.

Os elementos que o compõem - a água, o ar, o solo, o homem, as plantas, os animais - atuam num processo de interação permanente e segundo uma dinâmica particular de cada componente do conjunto, formando o corpo chamado meio ambiente. Essa movimentação é mútua e constrói o equilíbrio necessário ao meio natural saudável, que é indispensável a uma boa qualidade de vida.

È imprescindível, desta forma, que se considere, ao lado do tempo convencionado em datas, que é o tempo social, marcado por uma escala estabelecida pelo homem, um tempo próprio para o meio ambiente, que não seja registrado de forma prévia, abstrata e em espaços regulares, mas, de acordo com os eventos naturais e suas exigências particulares. 
201

Teixeira (2009, p.160) entende que "o tempo ambiental é um caso de temporalidade especial, com uma particular escala de medição’.

È um tempo não apenas quantitativo, mas qualitativo determinado por processos objetivos que lhe dizem respeito, como o movimento dos eventos e fatos o quais integram o meio ambiente e se relacionam, de forma direta, com o mesmo; e por processos subjetivos de caráter fisiológico, como as lembranças do passado, as sensações do presente e as perspectivas do futuro.

Para o autor (2009, p. 162) dois são os fatores mais relevantes para a consolidação da ideia de em escala especial de tempo ambiental, que é um tempo de antecipação efetiva aos fatos que o degradam:

a irreversibilidade ou a difícil reparação dos danos ocasionados ao bem jurídico ambiental;

os princípios da prevenção e da precaução, os quais são estruturantes do Direito do Ambiente.

Neste trabalho não trataremos do primeiro fator, uma vez eu concordamos plenamente que grande parte dos danos causados ao meio ambiente são de difícil reparação e na maioria dos casos danos irreparáveis.

Comentaremos, outrossim, o segundo fator, o qual pode ser vinculado às discussões relativas ao tempo, objeto deste estudo.

$\mathrm{Na}$ tentativa de solucionar as questões referentes ao meio ambiente, em especial a sua manutenção em condições dignas para as presentes e futuras gerações, compreendemos a importância da aplicação dos princípios da prevenção e da precaução, como "molas mestras" e medidas eficazes de proteção dentro de um tempo razoável.

Ambos têm o mesmo conteúdo finalístico, são muito presentes e estruturam o Direito Ambiental como um todo, orientando o funcionamento eficaz desse ramo jurídico pela ação antecipatória e acautelatória, buscando primordialmente evitar os danos; somente partindo para a seara da responsabilização pelos danos ocorridos em caso de impossibilidade de se evitar o resultado.

A referência inicial do princípio da prevenção, no plano da normatividade internacional, advém da Conferência das Nações Unidas sobre o Meio Ambiente Humano, 
adotada em Estocolmo, em junho de 1972, a qual estabelece, no princípio 6, a proibição de descargas de substâncias tóxicas ou de outros materiais que liberem calor, em quantidade ou concentrações tais, que o meio ambiente não possa neutralizá-los, para eu não se causem danos graves ou irreparáveis aos ecossistemas.

Já o da precaução é apontado no princípio 15 da Conferência das Nações Unidas sobre o Meio Ambiente e Desenvolvimento, adotada no Rio de Janeiro, em junho de 1992, em que reza: “com o fim de proteger o meio ambiente, o princípio da precaução deverá ser amplamente observado pelos Estados de acordo com suas capacidades". Ainda segundo o princípio, a ausência de certeza cientifica não deve servir de motivo para a não adoção de medidas eficazes diante do perigo de ocorrência de um dano irreparável ou de difícil reparação.

Na seara do direito interno, a origem do princípio da precaução está relacionada com a Lei Sueca sobre Produtos Perigosos para o Meio Ambiente, do ano de 1973. E, de forma mais sistematizada, com o Vorsorgeprinzip alemão, que é da década de 1980 e consiste em políticas públicas voltadas para a proteção das florestas cônicas contra as chuvas ácidas (Teixeira, 2009,p. 173).

Pelo visto, os princípios da prevenção e da precaução tem por função fundamental equacionar tais problemas temporais, evitando que a lentidão na tomada de providências eficazes - preventivas e precaucionais - comprometam o equilíbrio do meio ambiente. Viabilizar providências sem a adoção de postura pautada por tais princípios tem forte e real possibilidade de equivaler à negativa do direito à proteção.

A aplicação destes princípios, como já se disse, pode auxiliar na edificação da concepção de um tempo ambiental próprio, que possa observar os eventos que ocasionam modificações relevantes no meio ambiente e a eles antecipar-se, quando necessário. 
203

\section{CONSIDERAÇÕES FINAIS}

Embora de forma breve, pode-se observar que o estudo do tempo em si e suas relações com o direito e o meio ambiente é matéria que merecerá leituras exaustivas e necessárias à melhor compreensão do tema.

Assim, percebe-se que é através do presente que se constrói a justa medida dos tempos, consequentemente a justa medida da sustentabilidade. Entretanto, para que tal conceito possa ligar o presente e futuro é necessário que haja um ponto em comum entre as gerações. Conforme mencionado deve ser construído sob a égide da responsabilidade, impedindo a tentação ao determinismo e o perigo da eternização do presente instantâneo.

Vale ressaltar, que a responsabilidade referida diz respeito a uma preocupação com os presentes, bem como com as gerações futuras, não remetendo a idéia de culpa que liga ao passado.

Importa referir que a obra de François Ost é absolutamente relevante e necessária para iniciar-se a discussão sobre estas relações. O autor reforça a discussão sobre o tempo falando da importância de ligar-se aquilo que ameaça desatar-se, desligando o que se tornou inextricável, o tempo jurídico sabe pois operar "a contra-tempo", ou seja, contra o tempo natural, homogêneo, linear. Mas será que nesta relação direito, tempo e meio ambiente, o direito consegue seguindo o raciocínio de Ost ficar atento ao tempo ambiental? Esta pergunta ainda não foi possível responder.

Afinal, já cantava Cazuza: "Eu vejo o futuro repetir o passado (...) O tempo não para".

\section{BIBLIOGRAFIA}

AGOSTINHO, Santo, Bispo de Hipona. Confissões. Tradução de Maria Luiza Jardim

ALEXY, Robert. Teoria de los derechos fundamentales.Traducción de Ernesto Garzón Valdés. Madrid: Centro de estúdios políticos y constitucionales, 2002. Amarante. São Paulo:Paulus,2004. 
OST, François. A natureza à margem da lei.Lisboa:Piaget,1995.

OST, François. O tempo do Direito. Lisboa: Piaget, 1999.

PRIGOGINE,Ilya. O fim das certezas: tempo, caos e as leis da natureza.São Paulo:Editora Unesp,1996.

ROCHA, Leonel Severo. Tempo e diritto: dal normativismo all' autopiesi. Revista Stato e Diritti Nell 'Etá della globalizacione.Bruno libri.

TEIXEIRA, Antonio Edílio Magalhães. Processo Ambiental - Uma proposta de razoabilidade na duração do processo.Curitiba:Juruá,2009.

WHITEHEAD,Alfred North. O conceito de natureza. Tradução de Julio B. Ficher. São Paulo: Martins Fontes, 1994.

Artigo recebido em 01 de dezembro de 2011 e aceito em 03 de março de 2012. 